the cornea. These were first described by Herbert and later by Meyerhof." Herbert's description was published in the Trans. Ophthal. Soc. U.K., vol. XXIV, p. 67, 1904.

"These peripheral pits are the result of cicatrisation of trachomatous follicles at the limbus. Trachomatous follicles at the limbus are common enough, having the appearance of five or seven little rosettes at the upper part of the cornea. These rosettes and the pits, according to Egyptian experience, do not indicate any disease other than trachoma."

MacCallan notes that some writers (Bonnet and Trantas*) appear to regard the corneal manifestations of trachoma as important; it will be regrettable if they attach any other name than that of Herbert to the pits and marginal rosettes of the cornea which have been recognized in Egypt for a quarter of a century.

\title{
ABSTRACTS
}

$$
\text { I.-RETINA }
$$

(I) Larsson, Sven (Stockholm). - Operative treatment of detached retina by means of diathermy and trephining. (Operative Behandlung von Netzhautabhebung mit Elektroendothermie und Trepanation.) Acta Ophthal., Vol. VIII, p. $172,1930$.

(1) Larsson advocates his method of treatment as preferable to Gonin's as it does not depend on the localization and closure of holes in the retina. The principle involved is the old conception of producing an adhesive choroiditis, such as was attempted by the injection of chemical irritants or by galvano-cautery of the sclera. Experimentally, Larsson has shown that in the rabbit the application of diathermy to the sclera can produce vitreous changes without producing necrosis of the sclera. Seven cases in which the method was used are reported; in five, the author is satisfied with the result; in one there was improvement though the detachment remained over a large area ; in one there was no changc.

The procedure consists in dissecting up the conjunctiva over a segment corresponding as nearly as possibly to the detachment. The sclera corresponding to the detachment must then be exposed, muscles divided (at their tendinous insertions), if necessary. The globe may have to be rotated forward; this can be done by a suture

* Bonnet, Bulletin de la Societé d'Ophtalmologie de Paris, December, 1928 ; Trantas, Arch. d'Ophtal., July, 1930. 
in a tendinous insertion, and canthotomy may be necessary to complete the full exposure of the necessary amount of sclera. All bleeding being stopped (best done with diathermy) the small active electrode, which has a diameter of about 2 to $3 \mathrm{~mm}$. is applied over many points on the exposed sclera, for up to 5 seconds; the large electrode is kept on the leg. The current needed should be of such a strength as to produce no more than barely perceptible sparking; the effect of the diathermy on the sclera is to produce brownish discoloration at the point of contact. One or two trephinings of the exposed sclera complete the operation, the trephining being done to release subretinal fluid and as a prophylactic against a reactive rise in intra-ocular pressure. There is no bleeding when the trephine cuts through the choroid. Both eyes should be bandaged from 8-14 days. Pain after the operation may be severe. Atropine should be instilled the day after operation.

ArNold Sorsby.

(2) Gonin, J. (Lausanne).- Notes on detachment of the retina. (Remarques sur les décollements rétiniens). Ann. d'Ocul., Vol. CLXVII, p. 361, 1930.

(2) Gonin divides the subject as follows:-

Details observed in unoperated çases,

1. Vitreous opacities.

2. Retinal haemorrhages.

3. Holes in the retina.

4. Areas of choroido-retinitis.

Observations after operation,

5. Operation cicatrices.

6. Changes in the retina.

7. Function of the retina.

8. Post-operative complications.

1. Vitreous opacities.-Fairly well-defined grey-black opacities are common in highly myopic eyes without detachment of the retina. They are situated centrally and are believed to be the posterior elements of a detached vitreous drawn forwards. Quite different are the delicate grey-white opacities seen in the far periphery near the ora serrata, almost always to be seen in simple detachments. They are of grave significance in cases in which detachment of retina has not yet been discovered. More obvious opacities like little pieces of catton wool are sometimes seen in front of small retinal holes. A diffuse central vitreous haze, such as occurs in certain cases of choroiditis, is of grave prognosis in cases of retinal detachment which it complicates. 
2. Retinal haemorrhages.-Small retinal haemorrhages are nearly always to be seen in cases of recent retinal detachment and then nearly always indicate the region of the hole although they are not necessarily at its very margin. Such haemorrhages sometimes precede the discovery of a detachment and are common in the rapid extension of a detachment. These haemorrhages are more common in superior than in inferior detachments. The latter are not so commonly accompanied by separation of vitreous from retina as the former. This separation may detach the internal limiting membrane from the retina and so cause the haemorrhages.

Retinal detachment resulting from haemorrhage occurs in penetrating wounds, when the haemorrhage is uveal in origin, and also in nephritic or diabetic retinitis in which the haemorrhage is retinal. In the latter cases the detachment may be started by traction of a vitreous blood clot.

3. Retinal holes (déchirures).- - Holes in the retina are to be found in almost all cases of retinal detachment if sufficient time and care be taken in searching for them. Holes as large as twelve disc diameters across and as small as $\frac{1}{4}$-disc diameter are seen. The smallest holes may have an appearance like that of a small retinal haemorrhage except for a thin greyish edge of the rolled-up retina. In the far periphery they are often only found with great difficulty as the detached retina near the ora serrata transmits the red reflex, and contrast is slight. In 180 cases of detachment carefully examined, only 26 failed to reveal a hole. Of these, 8 had corneal opacities, and 5 displayed the retinal holes during the course of treatment. " Lance-shaped (à lambeau, lancéolaires), horse-shoe or semilunar holes are the commonest. The concavity is always towards the periphery. Occasionally a small retinal hole is seen with what is considered by Gonin to be a minute fragment of retina floating in the vitreous in front of it.

Holes may occur without the consequent development of detachment. Uncertainty is occasioned by cysts of the retina in some cases. A dome-shaped appearance with red centre and greyish surround is seen, but without any details of choroid structure which should usually be visible through a hole.

4. Choroido-retinitis.-Frequently one may see in cases of detached retina either disseminated patches of atrophy from choroido-retinitis or a row of patches of atrophy near the ora serrata, as commonly found in senile or myopic eyes without detachment. It is uncommon not to find such a spot in the neighbourhood of holes in the retina (especially in those " à lambeau.") Often the only pigment spot in the whole fundus is that near the retinal hole.

\footnotetext{
* The shape implied by the term à lambeau is possibly best described in English as tongue-shaped.
} 
5. The cicatrix of cautery puncture.-Examination of the eye five or six days after cautery-puncture shows usually a circular white area in the fundus surrounded by slight pigmentation and usually some small spots of haemorrhage. This corresponds with the site of puncture. Parallax shows the white area to be further out than its margin. It is formed by the conjunctiva covering the puncture. Occasionally it is red, when there has been undue haemorrhage under the conjunctiva. A white substance-like white of egg cooked hard-is sometimes present in or near this spot. If it is at one edge of the puncture, it is always the peripheral or anterior edge. It may be present at one of two punctures made on separate occasions and not at the other. If so, it is always at the more anterior puncture. This albuminous coagulum of the vitreous indicates the level to which the vitreous had become detached from behind forwards and is a useful guide to the antero-posterior site of the retinal hole. The circular white patch of cautery puncture in a few weeks becomes surrounded by a pigmented zone which indicates the area of adhesion between retina and choroid. This area is usually about three times the diameter of the puncture. The latter is about $2 \mathrm{~mm}$. wide. An area of adhesion results, which is about three times the diameter of the puncture. This area is wider on the peripheral side of any puncture, and is more extensive in peripheral punctures than in post-equatorial punctures, and in cases of recent detachment than those of some weeks' duration.

6. The condition of the retina.-At the first examination after operation, if the hole is closed, the retina is usually found to be in place even if the hole and detachment were of the upper part of the retina and if the retina happened to be widely separated from its bed. It is not known if this replacement takes place at the time of operation or if the fluid escapes from outside the retina during the few days before firm closure of the hole is produced. In cases of detachment of some weeks or months, the replacement of the retina is often not complete as shown by lack of choroidal pattern or slight irregularity of the surface of retina. Further in old cases, the extent of pigmentation around the puncture is less and this suggests incomplete or less firm attachment of the retina. Occasionally, retinal folds. radiate from the site of puncture but usually disappear, and only cause troublesome metamorphopsia if near the macula. Prognosis is less good when ballooning of the retina occurs around the cautery-puncture scar, for it indicates traction on the retina by vitreous and is likely to be followed by fresh retinal holes near the scar. In the case of old detachments, the escape of subretinal fluid by a cautery-puncture below may lead to retinal detachment above.

7. The return of visual function.- The scar of the puncture if within the region belonging to the physiological field of vision 
naturally produces a scotoma. This is of no more consequence than Marriotte's " blind spot." The return of the detached retina to place after only two weeks is followed usually by normal vision and colour perception although the latter may at first be subnormal. The older the patient and the longer the period of detachment, the less good is the visual result.

8. Complications of operation.-Gonin observed in six or seven cases severe vitreous haemorrhage after puncture operation in 300 cases. One was a haemophilic, two others involved father and son, a fourth had previously had spontaneous haemorrhage in the other eye. These haemorrhages usually occur six to ten days after the operation. They may be connected with the general condition-. hypertension, diabetes, - but especially with the site of the operation, i.e., near the venae vorticosae. In all, about 12 cases of fairly grave haemorrhage occurred in 300 operations. In some re-absorption of the haemorrhage occurs in a few weeks. In others it remained. Occasional mild iritis was noted, and two cases of glaucoma. In only one case was there complete loss of the eye owing to orbital cellulitis which extended into the wound.

Humphrey Neame.

(3) van Lint (Brussels).-Sclero-retinal thermo-cauterization in detachment of the retina. (La thermocauterisation scléro-rétinienne dans le décollement de la rétine). Arch. d'Ophtal., September, 1930.

(3) van Lint holds the opinion that sclero-retinal cauterization is the best surgical procedure in detachment of the retina. It is commonly termed Gonin's operation, though not quite accurately, as Gonin's technique consists in ascertaining the position of a hole in the retina and applying the cautery at this spot, in an endeavour to close the hole and thus prevent the passage of vitreous humour beneath the retina. van Lint maintains that the cauterization does not always close the rent : that in some cases no rent can be detected : that the cauterization induces a firm adhesion between the sclera and the retina causing a veritable re-attachment.

In this paper the author voices the unspoken opinion of other observers that undue importance has been given to the hole in the detached retina in relation to treatment by cauterization. $\mathrm{He}$ believes that the result does not depend so much on the closure of the rent as on the sclero-retinal synechia which is induced by the cauterization.

No argument has been advanced which proves conclusively the aetiological rôle of the retinal hole. Gonin records instances of cure in cases in which either no hole could be found, or it was so extensive that cauterization in its immediate neighbourhood was 
deemed preferable. Weill reports that he obtained good results in his early cases although the cautery had not touched the retinal tear.

van Lint agrees that certain cases appear to support Gonin's contention strongly; these are cases in which the retinal hole is situated outside the zone of the detachment, and in which cure resulted from cauterization of the rent.

The mode of action of the thermo-cautery is to provoke between the sclera and that portion of the retina reached by the cautery, an inflammation which is followed by firm adhesion between these two structures : the choroid might be said to play the part of cement. The solidarity of the adhesion which can be induced between the sclera and the retina is astonishing: van Lint compares it to actual soldering.

In spite of the statements of some authorities van Lint is emphatic in his opinion that thermo-cauterization is infinitely superior to chemical cauterization. He fully approves of Gonin's technique, and asks :- Is there any difference in adopting it when the aim is the closure of a hole in the retina or when it is the inducement of adhesions between the two membranes? It is simpler to aim at sclero-retinal cauterization only. Localization of the hole in the retina is sometimes difficult, requiring much time and attention, and when found it is essential to determine accurately its position on the surface of the sclera. The partisans of adhesive inflammation may undertake operation when the most careful search has failed to discover a retinal rent. Logically, those to whom the aetiological rôle of the tear in the retina is an article of faith cannot interfere in such cases. "There is no chance of closing a hole which does not exist."

In the writer's opinion Gonin's great merit lies not in having proved that detachment of the retina can be cured by cauterization of the rent in it, but in having demonstrated that the eye will tolerate without damage the introduction into the vitreous of a thermo- or a galvano-cautery.

\section{J. B. LAWFORD.}

(4) Stewens, Hermann (Dortmund).-Retinitis and detachment in nephritis of pregnancy. (Ueber die Ursache und des Verhalten der Netzhautentzündung und-ablösung bei Schwangerschaftsnierenerkrankung). Zeitschr. f. Augenheilk., Vol. LXXII, p. 293, 1930.

(4) Stewens reports as an interesting contrast two cases of nephritis of pregnancy, complicated by retinitis and bilateral retinal detachment. The feature common to both cases was the appearance of all the symptoms in the seventh month of 
pregnancy, the patients being previously in perfect health; oedema, increased blood-pressure, and albuminuria were present in both cases, in addition to the eye changes. In the course taken by the disesaes the two patients differed greatly. In the first case, a primipara, the blood-pressure reached $275 \mathrm{~mm}$., but there was no increased blood urea; the detachment was caused by choroidal lesions, star formation at the macula coming on later when the detachment was regressing. The eyes recovered practically completely and in spite of the apparently mild nature of the nephritis and of labour being induced, the general condition passed into chronic nephritis. The second case was a multipara ; there was marked increase of blood urea (178 mg. per cent.), and the bloodpressure was much lower being $220 \mathrm{~mm}$. The retinitis was severe, in contrast to the first case; the detachment regressed independently of the retinitis after interruption of pregnancy. In this case the apparently severe nephritis resolved completely, but the retina and optic nerve showed atrophy to a marked degree. Stewens sees in his cases evidence that detachment of the retina is independent in its cause and course from the retinitis, and that the retinitis itself is independent of the increased blood-pressure.

ARNold SORSBY.

\section{(5) Clapp, C. A. (Baltimore).-A case of tuberculous retinitis. Amer. Jl. of Ophthal., April, 1930.}

(5) Clapp's case is published because it proves " as far as one can prove in cases of tuberculosis of the eye, both the correctness of the diagnosis and the efficacy of the treatment." The patient when first seen in 1926 was a boy of 18 years of age who had been struck in the left eye four years previously by a base-ball. This eye had no P. L., was soft and showed evidences of old chronic iridocyclitis. There was a tuberculous family history. The right eye showed some vitreous opacities, old areas of choroido-retinal atrophy and in the lower nasal quadrant of the fundus, large fresh haemorrhages with numerous exudates. An intradermal tuberculin test ('001 mg.) was negative and the condition improved somewhat with rest although some haemorrhage remained. Six weeks later the haemorrhages were still present so a second tuberculin test was performed by a more experienced worker and a positive result was obtained with only $0001 \mathrm{mg}$. Injections were therefore given over a period of 6 months starting with $000001 \mathrm{mg}$. of bacillary filtrate and working up eventually to $1 \cdot 25 \mathrm{mg}$. After the first two months the haemorrhages had absorbed, though some retinitis proliferans remained. At the same time the patient demanded to have the opaque lens removed from his blind left eye. The eye remained 
inflamed after the operation and was excised. Histological examination showed typical tuberculous lesions with some giant cells, thus lending support to the diagnosis of the tuberculosis in the fellow eye. The author considers that this case teaches some important lessons (i) The necessity for great care in the performance of the tuberculin skin test, since the first one, performed by an inexperienced man gave a negative result (ii) The efficacy of tuberculin when properly administered (iii) That profuse retinal haemorrhage in young adults is usually the result of tuberculosis.

$$
\text { F. A. W -N. }
$$

\section{II.-PATHOLOGY}

(1) Allen, I. M.-A clinical study of tumours involving the occipital lobe. Brain, Vol. LIII, Part II, 1930.

(1) The following is Allen's summary of the results of examination of occipital lobe tumours from the National Hospital, Queen Square :-

(1) The clinical features of 40 cases of tumour of the occipital lobe have been reviewed, and their frequency, pathogenesis and significance discussed.

(2) The initial symptoms were epileptiform attacks in 30 per cent.; a visual aura or visual hallucinations in 12.5 per cent.; general mental impairment in 17 per cent.; headache in 35 per cent.; transient or progressive failure of vision in 15 per cent.; and strabismus is 2.5 per cent. In only 12.5 per cent. did the initial symptoms suggest that the visual paths were involved.

(3) The relative frequency of different symptoms of tumour of the occipital lobe was as follows:-Visual hallucinations, 25 per cent.; symptoms suggesting abnormality of the visual fields, 16 per cent.; epileptiform attacks, 52.5 per cent.; auditory hallucinations, 5 per cent.; abnormal tastes and smells, 12.5 per cent.; headache, 95 per cent. ; diplopia, 22 per cent. ; impairment of vision, 57 per cent.; disturbances of speech, 35 per cent.; spontaneous subjective sensations, 30 per cent. ; disturbances of motor functions, 52 per cent.; and mental symptoms, 55 per cent.

(4) Important findings on the examination of the patient were the following: Mental changes, 60 per cent.; contra-lateral homonymous defects of the visual fields, 94 per cent.; papilloedema or optic atrophy, 70 per cent. ; inequality of the pupils, 35 per cent. (contralateral pupil the larger in 25 per cent.); ocular pareses, usually of the external recti, 30 per cent.; nystagmus and 
nystagmoid jerkings, 35 per cent. ; disturbances of speech functions, 30 per cent. ( 50 per cent. of left-sided tumours) ; disturbances of sensation of the suprathalamic type, 55 per cent.; and minor degrees of motor disturbance usually in the contralateral limbs, 90 per cent.

(5) The changes in the visual fields found in the majority of cases occurred only in the contralateral halves of the fields. In individual cases the visual fields showed : (a) complete hemianopia up to the fixation point; $(b)$ incomplete hemianopia with spacing of the field for central vision; $(c)$ quadrantic effects; $(d)$ peripheral crescentic defects; and $(e)$ no abnormal changes. When vision was failing a concentric contraction of the visual fields was sometimes found added to the above variations.

(6) An attempt was made to group the symptoms and physical signs as focal, neighbourhood and those due to increased intracranial pressure. Focal symptoms and signs were limited to unformed visual hallucinations and distortions of the visual fields. Neighbourhood symptoms and signs were of considerable importance in localization, and with the exception of disturbances of speech were probably the result of oedema or vascular changes in the neighbourhood of the tumour, or of pressure upon adjacent structures, sometimes increased by raised supratentorial pressure. Symptoms and signs resulting from increased pressure in some cases were confusing and increased the risk of an error in localization.

(7) In the majority of cases symptoms of increased intracranial pressure dominated the clinical picture from the beginning; in a few epileptiform attacks occurred for some time; and in others there was a history of exacerbations of increased intracranial pressure for as long as two years.

J. H. P.

(2) Gabrielides, Const. (Athens). - Cysticercus within the vitreous. (Cysticerque intra-vitréen). Rev. gen. d'Ophtal., April, 1929.

(2) Gabrielides commences by giving his reasons for the designation of his case as above. "The above title has been given, and not 'cyst of the vitreous' or ' suprapapillary cyst' or ' rare ophthalmoscopic appearance,' because, after a minute study of the differential diagnosis between cysticercus of the vitreous and remains of the hyaloid artery, the canal of Cloquet, retinal or hyaloid haemorrhages, and even the rare forms of exudative retinitis, we come back to our original diagnosis of parasite of the vitreous." Having quoted this statement as showing the care which the author has taken in his diagnosis one may pass over the 
diagnostic points and come to the description of what the author saw : there is a sketch in the original. The patient was a woman of 55 years and the left eye, for which she sought advice, was totally blind from retinal detachment. The cyst was discovered in the right or "good" eye. Immediately in front of the disc there was a greenish iridescent cyst-like body. It was about one quarter the size of the disc. It was prominent about $16 \mathrm{D}$. and was attached at a point on the right-hand side of the disc. From this point it curved to form a kind of neck, which was followed by the principal portion composed of two more or less spherical swellings of different sizes. The whole cyst was in the vitreous, and on the front of it there was a brilliant white point. The fundus vessels passed behind the cyst, which swayed to and fro with movements of the eye and head. The white point was probably the receptaculum capitis at the bottom of which would be the head of the parasite. In spite of many examinations the author never saw any undulatory movements, nor did he ever see a head coming out of the receptaculum. From this and other facts (examination of faeces and of the blood, radiography of lungs, liver and orbit), including the fact that although watched for a considerable period no change took place in the cyst, the author concludes that the parasite is dead. An interesting and very carefully worked out case.

\section{ERnest Thomson.}

(3) Keilty, Robert A. M.D. (Washington, D.C.).-The bacterial flora of the normal conjunctiva with comparative nasal culture study. Amer. Jl. of Ophthal., October, 1930.

(3) Keilty's cultures were taken with swabs and planted aerobically on blood agar plates. One hundred normal patients were examined of whom 43 were sterile in both eyes. Of the remaining 57, the majority showed a haemolytic staphylococcus, with non-haemolytic streptococcus a bad second. The pneumococcus was absent, probably because the investigation was carried out during the warm summer months. In every case, there were obtained colonies of haemolytic staphylococcus from the nares while the non-haemolytic streptococcus was frequently found. The author is, therefore, of opinion that the majority of the eye contaminations were of nasal origin, the infection coming via the lacrymal passages or the lymphatics surrounding them. It was found that when the colonies were numerous in the eye cultures, they were also numerous in the nasal ones, but the converse did not hold true, many cases with heavy nasal cultures showing sterile conjunctivae.

F. A. W $-\mathbf{N}$. 


\section{III.-GLAUCOMA}

(I) Friedenwald, Jonas S. (Baltimore). - The pathogenesis of acute glaucoma. Arch. of Ophthal., May, 1930.

(1) Friedenwald puts forward in this paper an attractive explanation of the cause of acute glaucoma. He emphasises the necessity of separating this disease aetiologically from chronic glaucoma if one is to gain an insight into its true pathogenesis. The steps in the argument are briefly as follows. It has been abundantly shown by recent workers that the aqueous is a dialysate and that the intra-ocular pressure cannot, in the normal state of affairs rise higher than the osmotic pressure of the colloids in the blood. If it were so raised, say by artificial means, fluid would be absorbed from the aqueous by the blood in the uveal capillaries until equilibrium was once more restored. In acute glaucoma, however, we know that the intra-ocular pressure is much higher than can be accounted for by the blood colloids so that some other factor must come into play. The only possible one seems to be some breakdown in the osmotic barrier against the plasma proteins, affecting an extensive area of the intra-ocular capillaries. Serial sections of a number of eyes affected with acute glaucoma show haemorrhagic oedema of the ciliary body with serous or fibrinous exudate when the disease is in an early stage. In the later stages the coagulum is more compact and resembles hyalin. The inference therefore is that something has happened to the capillaries which has made their walls permeable to colloids. The most likely explanation is the presence of some endotheliotoxic substance in the blood. In confirmation of this, the author found that 0.1 c.c. of aqueous removed from the anterior chamber of a patient with glaucoma produced a definite swelling when injected into the skin, whereas control injections of saline and of aqueous removed from a patient with uncomplicated senile cataract did not. The presence of such a substance should also lead to an increase in the permeability of the walls of Schlemm's canal, but the approach to this canal is blocked by the iris, owing to its being pushed forward by the oedematous ciliary body. When this barrier is removed as in cases where the disease is cured by miotics without operation, the intra-ocular pressure will frequently become subnormal and remain so for six to twenty-four hours. In his second paper, published in the same volume, Friedenwald and Pierce give the results of experiments made, to test this hypothesis. Histamine, which has the effect of increasing the permeability of endothelium, was injected into the vitreous of various animals and found to produce marked oedema of the ciliary body with extravasations of serum and fibrin, the ciliary processes being much 
swollen, especially at their tips. In most instances the root of the iris was pushed forwards but not sufficiently to block the filtration angle, owing to the great depth of the anterior chamber and the small size of the ciliary body in animals. The histological changes were therefore similar to those found in glaucoma, but were less severe and more widespread than in human beings. Clinically, injections into the anterior chamber caused a short initial rise of pressure, followed by a marked drop, with massive oedema of the conjunctiva and cornea and mydriasis. When the injection was made into the vitreous, the rise of pressure lasted much longer and experiments with eserine which caused a partial block to the passage of fluid between the posterior and anterior chambers, seemed to show that there was no fall of pressure until the histamine had obtained access to the canal of Schlemm and thus opened up channels for the escape of the intra-ocular fluid.

\section{F. A. W-N.}

(2) Rossi (Naples). - The treatment of glaucoma by drugs and operation. (Terapia medica e chirurgica del glaucoma). Boll. d'Ocul., August, 1930.

(2) In this long and detailed paper Rossi gives the results of a variety of methods of treatment. He has tested ergotamin alone, and combined with calcium and adrenalin, glaucosan, and aminoglaucosan and comes to the conclusion that all are powerless to arrest the course of glaucoma.

In the matter of operation, he holds that the classical operation of von Graefe, iridectomy, is still unsurpassed in the treatment of acute glaucoma ; in the more chronic form Rossi has records about a large number of patients, operated on after the method of Lagrange, and an almost equal number by trephining. He notes that both these methods give good results; that there is no risk of further contraction of the field being caused immediately by the operation and that in the majority of cases the tension remains down and the vision in statu quo. In his tigures there is nothing to choose between the results obtained by these two methods; in both the successes were over 95 per cent.

Harold Grimsdale.

(3) Alajmo, Professor B. (Palermo).-The present position of the modern physico-chemical theory of glaucoma. (Lo stato attuale della moderna dottrina fisicochimica del glaucoma). Arch. di Ottal., April-May, 1930.

(3) The problem of the intra-ocular pressure has been attacked recently from two angles; it has been attempted to correlate the changes in the intra-ocular pressure with the varying osmotic blood-pressure, and also to base the changes on disturbances of the 
acid-base equilibrium of the blood and more particularly on the degree of concentration of the hydrogen ions in the blood with the consequent effects on the endocular fluids.

Alajmo, in this long paper, deals with both these theories; but dismisses the first in a few paragraphs; he concludes that osmotic pressure cannot have a decisive influence on the intra-ocular pressure but that it must serve to regulate the content of water.

With regard to the second part, he points out that the ocular contents, the aqueous and the vitreous humours, must be considered as colloids and therefore subject to the chemicophysical laws which govern such bodies. The aqueous must be treated as a hydrosol, and the vitreous as a hydrogel. Since it is generally agreed that the fluid of the vitreous is identical with the aqueous, any change in the latter implies a change in the solvent of the vitreous gel ; it is known that expansion of a colloid depends on the reaction of its solvent. Is the reaction of the aqueous humour changed in glaucoma, and is this change sufficient to account for the alteration in the pressure? It is this question which Alajmo raises and attempts to answer.

In a first series of experiments he attempted to alter the reaction of the aqueous in the direction of increased acidity. No result was obtained by giving drugs by the mouth; on the other hand intraperitoneal injection of large doses of acid phosphate of soda was followed by a fall of the intra-ocular pressure; this was more marked when the injection was subconjunctival; and when the drug was injected into the vitreous there was a marked fall which lasted for five or six weeks.

In a second series, alkaline solution was substituted for the acid; when the injection was made subconjunctivally, there was some rise of tension during the hours after, and then followed a slight fall. The tension became normal in a couple of days. After intravitreous injection, the immediate rise was followed by a fall, broken after about 15 minutes by a second rise; tension became normal in about an hour and then fell to sub-normal for 24 hours.

A third group of experiments was undertaken to investigate the results of altering the iso-electric point of the vitreous. Since the addition of any proteid to another or to a mixture of proteins will change the iso-electric of the whole, this will alter its behaviour to any given solvent. Previous investigators have lowered the iso-electric point of the vitreous by injections of varieties of gelatine.

Alajmo has made use of normal horse serum, serum from the subject, and white of egg in isotonic solution. In all these the immediate rise was followed by a fall to a tension considerably below normal, to regain normal limits in a few days.

Finally, Alajmo gives the results of subconjunctival injections 
of 2.4 per cent. solution of acid sodium phosphate. In all cases there was reduction of tension.

Summing up, Alajmo points out that the primary cause of glaucoma must be an increase of volume of the vitreous; given this, everything else follows. 'The blocking of the angle of the anterior chamber cannot be the first cause, for if it were the fluid collecting behind the point of exit would keep the anterior chamber deep, as is seen in buphthalmos. The alteration in the volume of the vitreous can be explained by the behaviour of colloids to variations in the solvent.

Harold Grimsdale.

(4) vom Hofe, K. (Jena).-Hypotony in so-called primary glaucoma. (Hypotonie beim Sog. primären Glaukom). Arch. f. Augenheilk., Bd. XCIX, July, 1928.

(4) In all the theories of glaucoma the dysfunction of the vascular system is a common factor. The tension of the healthy eye shows practically no departure from the normal under most conditions and the influence of the usual miotics on it is almost nil as measured by the tonometer. The occurrence of hypotony in advanced simple glaucoma is known. vom Hofe records cases of acute glaucoma and one-sided simple glaucoma with no signs of the disease in the fellow-eye in which miotics reduced the tension considerably below normal, especially in the unaffected eye. All this inclines him to the view that in cases of unilateral glaucoma, if miotics produce hypotony in the apparently healthy fellow eye, a certain predisposition of the eye to glaucoma may be suspected.

$$
\text { D. V. GIRI. }
$$

(5) Green, A. S., L. D. and M. I. (San Francisco).-Glaucoma. Factors underlying success in trephining. Arch. of Ophthal., March, 1930.

(5) The Green brothers started an investigation in 1927 to determine which of the operations for glaucoma gave the best results, the cases studied dating back to 1911 . The results were slightly in favour of trephining and curiously enough were better during the earlier than during the later years of their practice. Examination of records and patients revealed that the successful cases were those which had a small peripheral iridectomy, while an iridotomy was found to give just as good results as an iridectomy. The following technique has been worked out and found to give good results. " A $1.5 \mathrm{~mm}$. trephine is generally the best size and it should be superlatively sharp." The ordinary procedure is followed up to the point where the cornea is split but the trephine is placed so that it leans to the scleral rather than to the corneal side so that the disc is hinged at the limbus. The moment the iris 
prolapses into the trephine opening, the iridectomy or iridotomy is to be performed without allowing the prolapse to increase and without taking hold of the iris by forceps.' All that is necessary is to snip the iris at the scleral side. The disc should not be removed until the iris has resumed its position in the anterior chamber. As a rule this happens after iridectomy without further manipulation, if not, the eyeball may be gently massaged under the lid. The conjunctiva is closed with a water-tight suture and after-treatment follows the usual lines.

$$
\text { F. A. W -N. }
$$

(6) Greenwood, Allen (Boston), Combined iridencleisis and sclerotomy for chronic glaucoma. Amer. Jl. of Ophthal., April, 1930.

(6) Greenwood considers that while trephining is the best operation for chronic glaucoma, better results are obtained in congestive glaucoma by the following procedure, particularly in old patients with a shallow anterior chamber. A conjunctival flap is made as for trephining but the cornea is not split. A small narrow-bladed, Graefe knife is then inserted, one millimetre from the limbus and two millimetres from the top of the cornea. It is carried across the anterior chamber, the counter-puncture being made a little further back in the sclera than the puncture, and the section completed with the knife turned slightly backward so as to make a long lip of scleral tissue. A good bite of this is then removed with a Lagrange punch or with special curved scissors. The iris is grasped with forceps near the pupillary margin and drawn out until the sphincter is well outside the wound, when a radial cut is made in the iris extending nearly to the base on each side of the forceps. The portion within the grasp of the forceps is smoothed out with the black side uppermost and the rest of the iris is carefully returned to the anterior chamber, thus leaving a narrow tongue of iris between the lips of the wound and lying on the sclera. The conjunctiva is united by a continuous suture.

\section{F. A. W $-\mathbf{N}$.}

(7) Kronfield, Peter Clemens (Vienna). - The intra-ocular tension following puncture of the anterior chamber. Arch. of Ophthal., February, 1929.

(7) Kronfield's experiments were performed on human eyes and the aqueous was withdrawn by a fine needle attached to a syringe, the needle being introduced obliquely, so as to secure a water-tight puncture. It was found that after withdrawal of enough aqueous to cause apparent emptying of the anterior chamber, the original pressure was reached again in 65 to 75 minutes. In 90 minutes the pressure was 6 to $8 \mathrm{~mm}$. above the normal, and during 
the succeeding four hours it came down slowly to normal again. Transient disturbances of the cardio-vascular system had a marked effect on the behaviour of the intra-ocular pressure after puncture, the rise of tension being greater in cases with arterial congestion of the eye, and less in cases rendered avascular with epinephrine. This is probably because the permeability of the lining cells of the capillaries is greater in the presence of vascular congestion. Hagen has stated that the anterior chamber of a normal eye is restored to its full depth four minutes after puncture, but the author cannot confirm this observation. By withdrawal of aqueous at various times after the first puncture, he found that 20 minutes after the first puncture, the anterior chamber contained only 50 to 60 per cent. of its original volume. Magitot considers that the intraocular tension is not due to the aqueous humour, but the following experiment by the author contradicts this. The eye used was one which had normal vision but was to be removed on account of a sarcoma of the choroid. The needle of a Wessely manometer was inserted into the anterior chamber and the intra-ocular tension measured for 15 minutes. The puncture needle was then introduced and portions of aqueous removed until the anterior chamber was almost empty and the pupil had begun to contract. The tension was now $-5 \mathrm{~mm}$. $\mathrm{Hg}$ owing to the cornea and sclera being too rigid to collapse. Within 30 minutes the tension had risen to $+5 \mathrm{~mm}$. Hg. It was found by experimental reintroduction of aqueous after the puncture that approximately $165 \mathrm{c} . \mathrm{mm}$. of aqueous were required to bring the tension up to $+5 \mathrm{~mm}$. $\mathrm{Hg}$. The author deduces therefore that this amount of aqueous should be found in the anterior chamber 30 minutes after puncture, a figure which was confirmed by experiment, the actual amounts in three observations being 160,165 , and $180 \mathrm{c} . \mathrm{mm}$. The refilling of the anterior chamber can thus be accomplished without any contribution from the vitreous body.

$$
\text { F. A. W -N. }
$$

\section{IV.-MISCELLANEOUS}

(1) Vogt, Alfred (Zürich).-Copper and silver accumulated in the eye, liver, spleen and kidney as sign of pseudosclerosis. (Kupfer and Silber augespeichert in Auge, Leber, Milz und Nieren als Symptom der Pseudosclerosis). Klin. Monatsbl. f. Augenheilk., Bd. LXXXIII, October-November, 1929.

(1) In the April number of the same periodical Vogt summarized his investigation into the cause of the pigment ring in pseudosclerosis as under: 
"Under the slit-lamp microscope the pigment ring in pseudosclerosis shows characteristic appearances of colour which range from brown and yellow to green and ultramarine blue and correspond exactly with those produced in the cornea by silver protein solutions (Silbereiweisslosüngen) incorporated into it. Further, the latter show a tendency to diffuse in the vicinity of Descemet's membrane. These appearances of colour are of so typical a nature that it may. be concluded that the pigment of pseudosclerosis is identical with silver compounds incorporated in the cornea.

Not only clinically but also chemically the pigment of Descemet's membrane can be recognized as due to silver. Rumpel, Söldner and Weinland have already demonstrated this as regards pigmentation of internal organs.

The copper cataract noted in pseudosclerosis by Siemerling, Oloff, Vogt and Jess is to be associated with large accumulations of copper found in the liver by Rumpel and Söldner."

Since then the patient, Elise U., discussed in extenso in the above contribution, died at the age of 61 in the Medical Clinic and Vogt had the liver and kidney of the patient examined chemically with the result that the liver was found to contain the enormous quantity of $29 \mathrm{mg}$. copper per $100 \mathrm{~g}$. liver and $1 \cdot 2 \mathrm{mg}$. silver per $100 \mathrm{~g}$. liver, $10 \mathrm{mg}$. silver and $1.7 \mathrm{mg}$. copper per $100 \mathrm{~g}$. kidney.

This is a triumph for slit-lamp microscopy but for which in the case of Elise U. the liver and kidney would not have been tested for copper and silver and the only instance in medicine of this unique clinical picture would have remained undiscovered. Vogt found copper in the lens and silver in the cornea in the same case.

D. V. GiRI.

(2) Monjukova, N. K., Fradkin, M. J., and Heyfetz, M. J. (Moscow).-The reticulo-endothelial system and the eye. (Das reticulo-endotheliale System und das Auge.) Klin. Monatsbl. f. Augenheilk., Bd. XXXIII, October-November, 1929.

(2) This system is constituted by Kupfer's cells of the liver (Kupferschen Zellen der Leber), the endothelium and reticular cells of the spleen, bone-marrow and the lymphatic nodes, the endothelium of the adrenals, and the less fixed and mobile cells of the body at present known as tissue histiocytes and blood histiocytes. To belong to this system the cell must be not only phagocytic but also metabolic in function.

Lately, the importance of the R.E.S. (reticulo-endothelialsystem) has aroused extraordinary interest. Experiments show that the anti-bodies constitute a product of the internal secretory activity of the R.E.S. Determination of the functional capacity of the R.E.S. gives a measure of the powers of defence of the body, 
enables one to follow the fight of the body against infection, to know beforehand its probable termination, and forms a criterion for intervention. The R.E.S. has the property of taking up negatively laden colloids introduced into the blood. Congo-red is such a colloid capable of great dispersion and absolutely harmless to the body.

The normal Congo-red index for human blood has been found to be 50-70 per cent. (For the details of the test the reader is referred to the original.) According to Monjukova, Fradkin and Heyfetz an index of over 75 indicates a depression of function of the R.E.S. They have determined this index in a number of diseases of the eye and tabulated their findings. Depression of function of the R. E. S. in four cases of tuberculous uveitis, three of sympathetic ophthalmitis, one of von Hippel's disease, one of buphthalmos and one of traumatic irido-cyclitis was noted. One case of interstitial keratitis showed a scarcely appreciable depression.

The authors lay special stress on their finding in sympathetic ophthalmitis. Latterly, Guillery has worked out experimentally the connection between tuberculous intoxication and sympathetic ophthalmitis. The authors foresee the possibility of deriving practical guidance from the functional testing of the R.E.S. for pre-diagnosing a brewing sympathetic ophthalmitis and as to whether or not and when to enucleate an eye.

They also draw our attention to the influence of the R.E.S. on transplants such as those of the cornea and on protein therapy so often employed in ophthalmology.

D. V. GiRI.

\section{BOOK NOTICE}

Opticks. By SiR ISAAC NewTon. Reprinted from the Fourth Edition, with a foreword by Prof. Albert Einstein, and an introduction by Professor E. T. Whitaker, F.R.S. London: G. Bell \& Sons, Ltd. 1931. Price, 6s.

Newton's classical experiment of producing the spectrum of sunlight with a glass prism was first published in the Philosophical Transactions of the Royal Society in 1672. His deduction that " to the same degree of refrangibility ever belongs the same colour, and the same colour ever belongs the same degree of refrangibility" was vehemently criticised by Hooke. Newton's dislike of controversy nearly led him "to be no farther solicitous about matters of philosophy." Fortunately, however, his scientific curiosity could not be abated, and we know that the first manuscript of a 